\title{
Effect of different activation agents on the pollution removal efficiency of date seed activated carbon: process optimization using response surface methodology
}

\author{
Hajar Al Subhi ${ }^{1}$ Mohammed Salim Adeeb ${ }^{2} \cdot$ Mukesh Pandey $^{3} \cdot$ Hafez Al Sadeq ${ }^{1}$. Deepak Kumar ${ }^{4}$. \\ Sudheer Kumar Shukla' ${ }^{10}$
}

Received: 5 February 2020 / Accepted: 11 June 2020 / Published online: 23 June 2020

(c) The Author(s) 2020

\begin{abstract}
Activated carbons are currently one of the most widely used materials for water and wastewater treatment because of their high specific surface area and moderate cost. This study is about the comparison of different activation methods on the pollution removal efficiency of date seed activated carbon using response surface methodology (RSM). The date seeds were carbonized in a muffle furnace at $300{ }^{\circ} \mathrm{C}$ for $1 \mathrm{~h}$ to produce carbon. Then, the chemical activation was carried out using $1 \mathrm{~N}$ solution of $\mathrm{H}_{3} \mathrm{PO}_{4}, \mathrm{HNO}_{3}, \mathrm{H}_{2} \mathrm{SO}_{4}$ separately for $24 \mathrm{~h}$. Activated carbons were ground in a grinder to convert it to powder form, and after that, it was sieved using 75 microns sieve. Physical properties like pore size and surface area were studied using scanning electron microscopy (SEM). Pollution removal studies were carried using the Jar test, and the experiments were designed using RSM. The results show that the maximum COD reduction of $98.58 \%$ was obtained when $\mathrm{H}_{2} \mathrm{SO}_{4}$ was used as an activation agent. The results show that the carbon activated by $\mathrm{H}_{2} \mathrm{SO}_{4}$ shows the highest removal than its counterparts. The optimum dose was optimized using RSM and found to be $300 \mathrm{mg} / \mathrm{l}$, and the optimum reaction time was $10 \mathrm{~min}$. By this set of conditions, $96.3 \%$ of COD removal could be achieved. The results are confirmed by SEM studies, which show a high surface area, more pores, and the presence of a high amount of carbon in the $\mathrm{AC}$ prepared using $\mathrm{H}_{2} \mathrm{SO}_{4}$.
\end{abstract}

Keywords Activated carbon · Date seed · Pollution removal · Response surface methodology · Waste to product

\section{Introduction}

Water pollution is the cause of great concern for modern society. Effluent discharged from industries contains various contaminants, which can cause environmental problems like eutrophication, algal bloom, and health threat to humans when released into the water bodies (Thamilselvi and Radha

Sudheer Kumar Shukla

sudheerkrshukla@gmail.com; sudheershukla@nu.edu.om

1 Department of Civil and Environmental Engineering, College of Engineering, National University of Science and Technology, Muscat, Oman

2 Department of Mechanical and Industrial Engineering, College of Engineering, National University of Science and Technology, Muscat, Oman

3 School of Energy and Environment Management, Rajiv Gandhi Technological University, Bhopal, India

4 Galgotias College of Engineering and Technology, Greater Noida, India
2017). To mitigate adverse environmental effects, generally, conventional water treatment processes are employed to reduce the level of contaminants found in water. These methods include (but not limited to) biochemical processes, membrane filtration, coagulation, sedimentation, oxidation, adsorption by activated carbon (AC). Among these methods, the adsorption process by AC is widely used, especially after secondary treatment, and is well known to be useful for water and wastewater treatment (El-Sayed et al. 2014; Njoku and Hameed 2011; Thamilselvi and Radha 2017). Adsorption process by AC has several advantages over other methods. These advantages include less land area requirement for the AC; the adsorption process is not affected by toxic chemicals, and the AC is capable of reducing a high concentration of organic contaminants from water (El-Sayed et al. 2014). Activated carbons (ACs) are considered as the general adsorbent due to their broad range applications. These versatile materials are characterized by large specific surface areas and large pore volumes. Their principal property is to adsorb molecules as well in the liquid phase as in the gaseous phase 
(Sudaryanto et al. 2006). Activated carbon can be prepared from almost any organic material rich in carbon and preferably with low content in the inorganic matter (Li et al. 2008). There are plenty of reported studies for activated carbon preparation from a variety of agricultural waste such as date stones (Bouchelta et al. 2008; Haimour and Emeish 2006), peach stones (Soares Maia et al. 2010), rice straw (Uçar et al. 2009), pistachio-nut shells (Lua and Yang 2005), apricot stones (Şentorun-Shalaby et al. 2006), cherry stone (Olivares-Marín et al. 2006; Tancredi et al. 2004), pecan shell (Corcho-Corral et al. 2006), corncob (Deng et al. 2009), cotton stalk (Benadjemia et al. 2011), coffee bean husks (Zięzio et al. 2020), plain tobacco stems (Zięzio et al. 2020), olive bagasse (Saleem et al. 2019), and almond shells (Mohan et al. 2011). Different chemicals ( $\mathrm{KOH}, \mathrm{K}_{2} \mathrm{CO}_{3}, \mathrm{NaOH}$, $\mathrm{Na}_{2} \mathrm{CO}_{3}, \mathrm{AlCl}_{3}, \mathrm{ZnCl}_{2}, \mathrm{MgCl}_{2}, \mathrm{H}_{3} \mathrm{PO} 4$, and $\mathrm{H}_{2} \mathrm{SO}_{4}$ ) are used as a chemical agent for the activation of carbons (Hadoun et al. 2013). Acid-activated pecan shell-based carbons show higher adsorption for organic matter than the commercially available activated carbon (Bansode et al. 2004). Specific properties of activated carbon depend on the raw material and the activation process employed (De Gisi et al. 2016). Several studies show that the activated carbon prepared at the lower temperature of carbonization exhibits better characteristics compared with activated carbon prepared at the higher temperature (Valizadeh et al. 2016; Islam et al. 2017; Norouzi et al. 2018; Liew et al. 2019). The chemical activation agent first degrades the cellulosic material, and the process of carbonization creates a suitable pore structure as a result of dehydration (Azevedo et al. 2007). Therefore, chemical activation affects the adsorption of activated carbon and ability based on differences properties such as surface area, density, $\mathrm{pH}$, and conductivity (Puziy et al. 2002). Phosphoric acid imparts cation exchange capacity, making it chemically stable both in acidic and base media in addition to its thermal stability (Puziy et al. 2002). Oman is one of the largest producers of date. Date seeds are the waste material produced after processing dates and freely available, which makes them preferred material for activated carbon production in Oman. Though there are plenty of studies reported about activated carbon around the world, however, there is a shortage of studies in Oman. Also, there is a lack of data concerning the characteristics of the adsorbents such as their average particle size or specific surface area (De Gisi et al. 2016). Response surface methodology is a powerful tool to the optimization of process parameters, and it helps in selecting a set of the most suitable parameters in a given condition (Ghorbani et al. 2020; Karimifard and Alavi Moghaddam 2018; Topal and Arslan Topal 2020).

Moreover, there are not much-reported studies on the application of RSM for optimization of process parameters in adsorption study using activated carbon made from date seed using different activation agents. We reported activated carbon production from coconut shells, orange peels, and banana peels using $\mathrm{H}_{3} \mathrm{PO}_{4}$ as an activation agent in our previous study (Shukla et al. 2020). The present study is aimed to ascertain the effects of varying activation agents on the pollution removal efficiency of date seed activated carbon using response surface methodology. In this study, response surface methodology was used to optimize different process parameters to achieve optimum removal. Physical properties of activated carbon were also studied using a scanning electron microscope.

\section{Materials and methods}

Date seeds were selected as raw material for the production of activated carbon because of its ample availability in Oman. Carbon was activated using three chemical activation agents $\mathrm{HNO}_{3}, \mathrm{H}_{3} \mathrm{PO} 4$, and $\mathrm{H}_{2} \mathrm{SO}_{4}$. Physical properties, like surface area and carbon content, were studied using an electron scanning microscope (SEM). Pollution removal experiments were designed by using response surface methodology (RSM) to optimize the process parameters for optimum removal. The detailed methodology is given below.

\section{Preparation of activated carbons}

Raw material date palm seeds were collected farm in Nizwa, Oman. First, the date palm seeds were washed with deionized water to remove impurities and dried in an oven at $110{ }^{\circ} \mathrm{C}$ for $24 \mathrm{~h}$. The dry materials were then crushed. After that, the date seeds were carbonized in a muffle furnace at $300{ }^{\circ} \mathrm{C}$ for $1 \mathrm{~h}$ to produce carbon. Then, the produced material was cooled at room temperature for $30 \mathrm{~min}$, then washed with distilled water, and then dried in the oven at $105{ }^{\circ} \mathrm{C}$ for $1 \mathrm{~h}$. For chemical activation, the material was soaked into $1 \mathrm{~N}$ solution prepared from three different activation agents $\left(\mathrm{H}_{3} \mathrm{PO} 4, \mathrm{HNO}_{3}\right.$, and $\left.\mathrm{H}_{2} \mathrm{SO}_{4}\right)$ separately for $24 \mathrm{~h}$ and then again heated in the oven at $110^{\circ} \mathrm{C}$ for $1 \mathrm{~h}$. After that, the samples were heated in a muffle furnace at $300{ }^{\circ} \mathrm{C}$ for $1 \mathrm{~h}$ to achieve surface activation. After heating, the samples were cooled at room temperature. Then, the samples were soaked again in $100 \mathrm{ml}$ of distilled water with $1 \mathrm{~g}$ of sodium bicarbonate for $24 \mathrm{~h}$ to remove excess acid from the sample. Samples were then washed separately with distilled water for 4-5 times until the $\mathrm{pH}$ becomes neutral. The washed samples were dried at $110^{\circ} \mathrm{C}$. The activated carbon of each material was milled and sieved to $75 \mu \mathrm{m}$, mesh size. Dried and sieved samples were stored in the clean and dry container for further experiments. 


\section{Physical properties of AC}

The physical properties of AC like surface area and carbon content were studied using SEM at Central Analytical and Applied Research Unit, Sultan Qaboos University (CARRU SQU). One sample was taken from activated carbon made using each activation agent $\left(\mathrm{H}_{3} \mathrm{PO}_{4}, \mathrm{HNO}_{3}, \mathrm{H}_{2} \mathrm{SO}_{4}\right)$ for the study.

\section{Design of pollution removal experiment}

Response surface methodology (RSM) is a statistical method that uses quantitative data from appropriate experiments to develop a regression model relating the experimental response to the process variables. A standard RSM design, central composite design (CCD) was used to design the number of experiments and to optimize the process conditions. The factors were the amount of activated carbon $(100 \mathrm{mg} / \mathrm{l}, 200 \mathrm{mg} / \mathrm{l}, 300 \mathrm{mg} / \mathrm{l})$ and time (10 min, $20 \mathrm{~min}$, $30 \mathrm{~min}$ ) with three different activation agents $\mathrm{H}_{3} \mathrm{PO}_{4}, \mathrm{HNO}_{3}$, $\mathrm{H}_{2} \mathrm{SO}_{4}$. The percentage of COD was taken as a response.

\section{Pollution removal efficiency}

Jar tests were conducted to evaluate the pollution removal efficiency of different activated carbons. Sixty-three samples were taken with different chemical activations and varying amounts of AC $100 \mathrm{mg} / \mathrm{l}, 200 \mathrm{mg} / \mathrm{l}, 300 \mathrm{mg} / \mathrm{l}$ as per the RSM design. The measured quantity of activated carbon was added into the flask, which already contains 1-liter wastewater. After adding activated carbon, the sample was shaken at $120 \mathrm{rpm}$ for different times as per the RSM design. After stirring, the samples were filtered using 40 number Whatman filter paper. Water quality parameters like $\mathrm{pH}$ and COD were analyzed using AWWA/APHA standard methods (APHA/AWWA/WEF 2005).

\section{Results and discussion}

\section{Physical properties of activated carbon}

\section{Physical properties of activated carbon prepared using $\mathrm{HNO}_{3}$}

A scanning electron microscopy (SEM) technique was used to investigate the surface physical morphology of activated carbons. Scanning electron microscopic pictures of date seeds activated carbon produced by chemical activation using $\mathrm{HNO}_{3}$ are presented. As shown in Fig. 1, there are channel-like walls on the surface of raw material and pores of different size and shapes also has different size of grains in the surface area; also, it shows the presence of various elements with a high amount of carbon around $75 \%$. The external surface has a crack and a lot of grains particles with irregular and heterogeneous surface morphology with a well-developed porous structure.
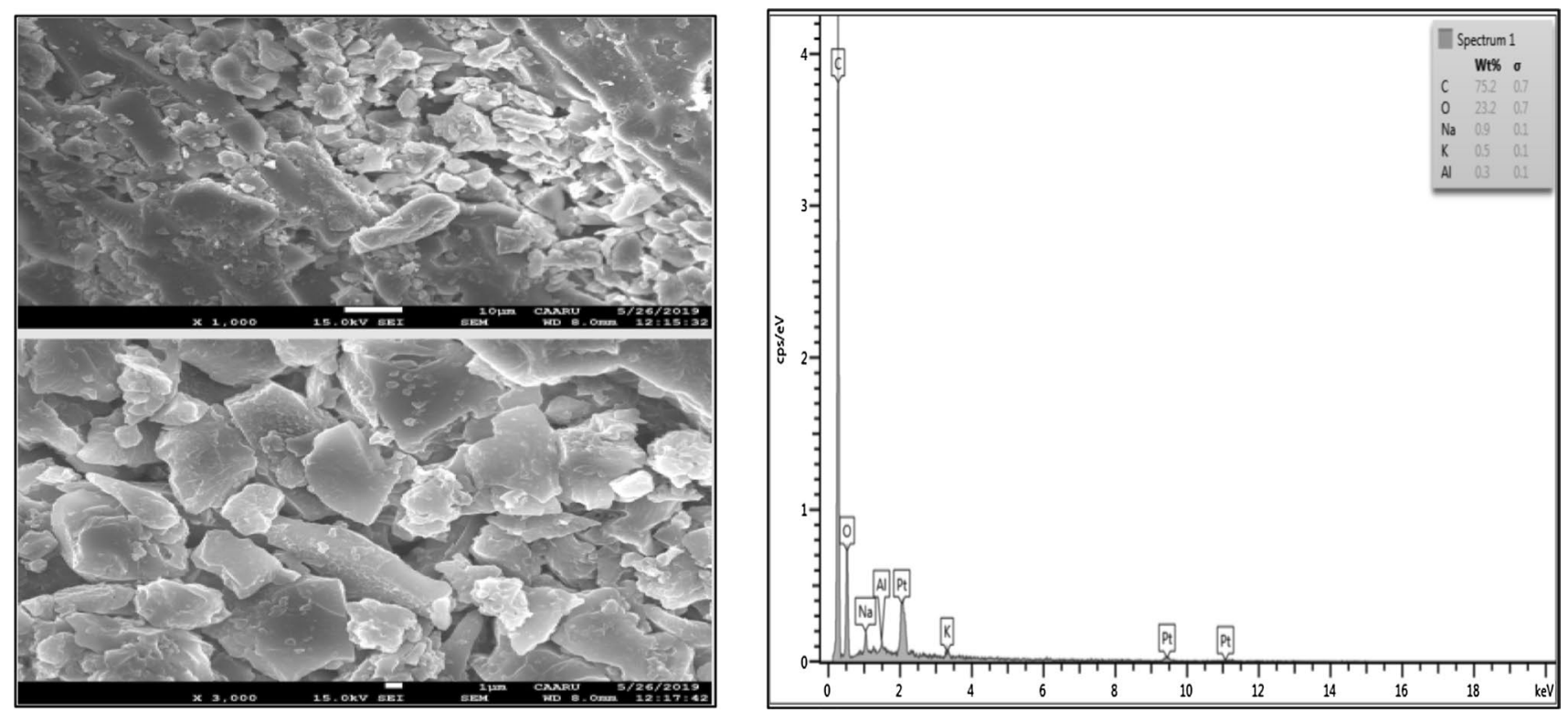

Fig. 1 Scanning electron microscopic analysis of activated carbon prepared using $\mathrm{HNO}_{3}$ as an activation agent 


\section{Physical properties of activated carbon prepared using $\mathrm{H}_{3} \mathrm{PO}_{4}$}

A scanning electron microscopy (SEM) technique was used to investigate the surface physical morphology of activated carbons. Figure 2 illustrates the SEM photographs of activated carbon prepared using $\mathrm{H}_{3} \mathrm{PO}_{4}$. As shown in Fig. 2, the surface was smooth, and there was a channel-like wall on the surface of raw material and pores of different sizes, shapes, and small grains. The presence of various elements with a high amount of carbon (around 78.8\%) can be seen.

\section{Physical properties of activated carbon prepared using $\mathrm{H}_{2} \mathrm{SO}_{4}$}

As shown in Fig. 3, activated carbon has a lot of pores with different sizes and shapes. As shown in the micrographs, the shape of the external surface of the activated carbons like a wall has cracks and some grains in various sizes in some holes and large numbers of voids. And the activated carbon morphology comes as a bone. The analysis of date seeds activated carbon activated by $\mathrm{H}_{2} \mathrm{SO}_{4}$, shown in Fig. 3, showed the presence of various elements along with a high amount of carbon $82.6 \%$.

Activated carbon made using different activation agents shows the significant formation of pores and rough surface and contains a high amount of carbon content. Moreover, activated carbon produced using $\mathrm{H}_{2} \mathrm{SO}_{4}$ shows more voids and $82.6 \%$ and carbon, which is highest among all. The effects of the rough surface and high amount of carbon by this activated carbon were attributed to the high removal of COD during pollution removal studies.

\section{Pollution removal efficiency}

As per the RSM design, sixty-three samples were taken for different chemical activations and varying amounts of AC $100 \mathrm{mg} / \mathrm{l}, 200 \mathrm{mg} / \mathrm{l}$, and $300 \mathrm{mg} / \mathrm{l}$ with different time (10 $\mathrm{min}, 20 \mathrm{~min}$, and $30 \mathrm{~min}$ ). The results obtained after the experiments are discussed below.

\section{COD removal efficiency of activated carbon prepared using $\mathrm{H}_{3} \mathrm{PO}_{4}$}

The relationship between different amounts of activated carbon, which are activated by $\mathrm{H}_{3} \mathrm{PO}_{4}$ and the time on-removal efficiency of COD, are presented in Fig. 4. The highest percentage of COD removal $95.74 \%$ was observed when the activated carbon is $200 \mathrm{mg} / \mathrm{l}$ and time is $30 \mathrm{~min}$. Around $91.12 \%$ was the lowest removal at 10 min reaction time and $100 \mathrm{mg} / \mathrm{l}$ of activated carbon dose. A similar study was carried out by Mohammad Razi et al. (2018) with $\mathrm{H}_{3} \mathrm{PO}_{4}$ as an activation agent, and they observed 60\% COD removal. It seems activation temperature plays a vital role as they activated at $550{ }^{\circ} \mathrm{C}$; however, in the present study, we used a $300{ }^{\circ} \mathrm{C}$ temperature for activation.
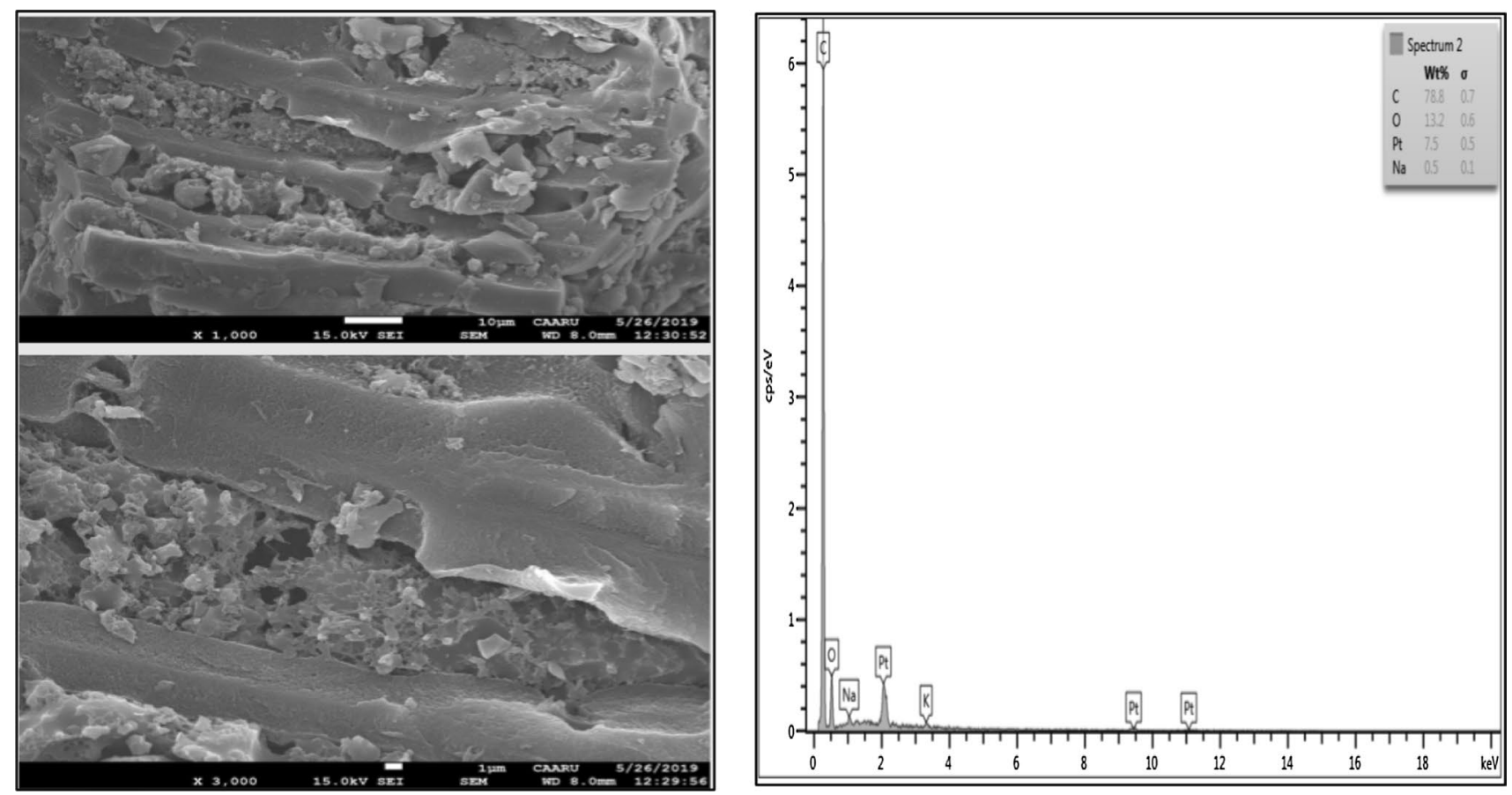

Fig. 2 Scanning electron microscopic analysis of activated carbon prepared using $\mathrm{H}_{3} \mathrm{PO}_{4}$ as an activation agent 

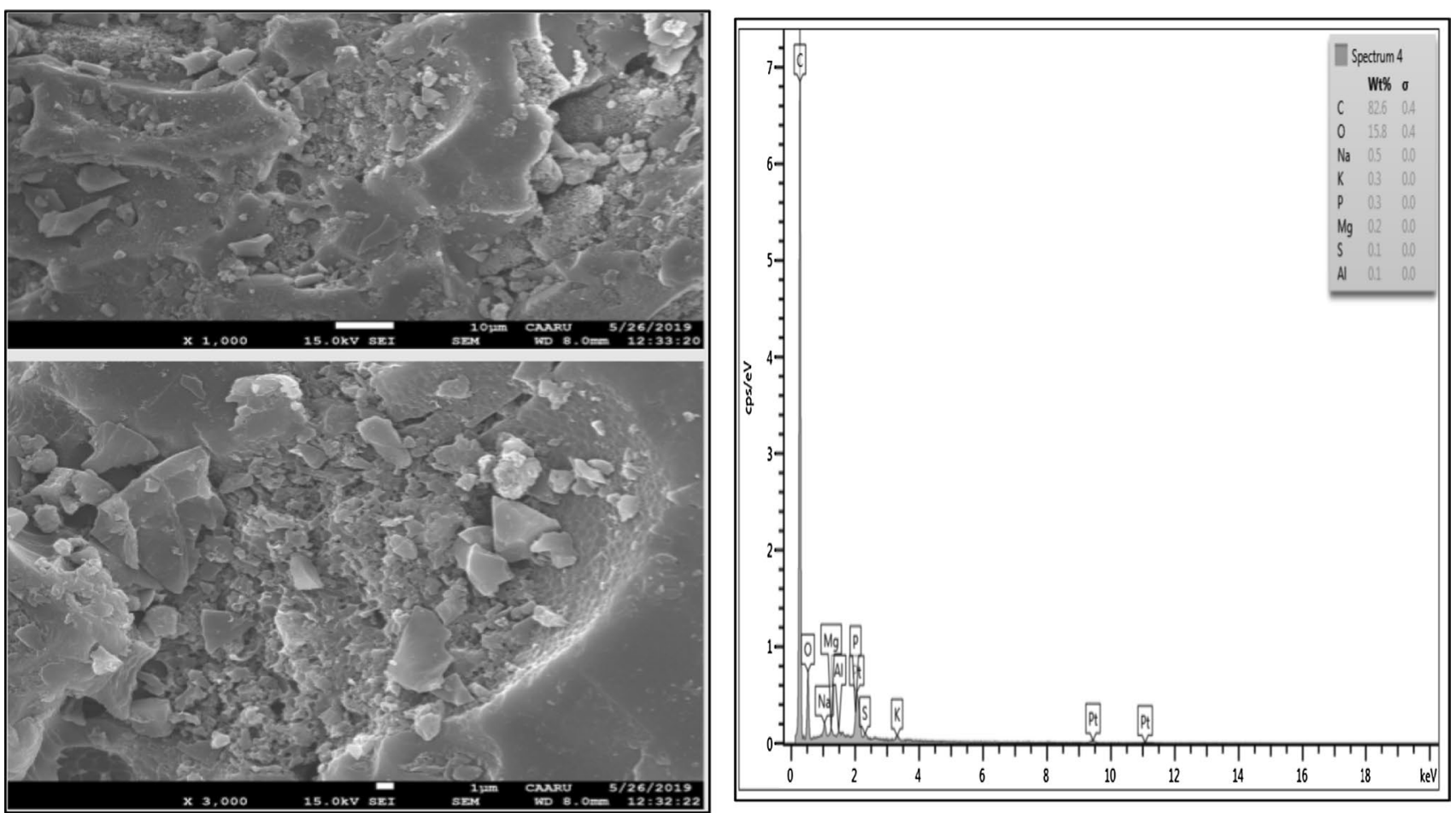

Fig. 3 Scanning electron microscopic analysis of activated carbon prepared using $\mathrm{H}_{2} \mathrm{SO}_{4}$ as an activation agent

\author{
Design-Expert $\otimes$ Software \\ Trial Version \\ Factor Coding: Actual \\ COD (\%) \\ - Design points above predicted value \\ Design points below predicted value \\ $88.4547 \square 98.579$
}

$\mathrm{X} 1=\mathrm{A}:$ Amount of Activated Carbon $\mathrm{X} 2=\mathrm{B}$ : Time

\section{Actual Factor}

C: Activated Agents $=\mathrm{H}_{3} \mathrm{PO}_{4}$

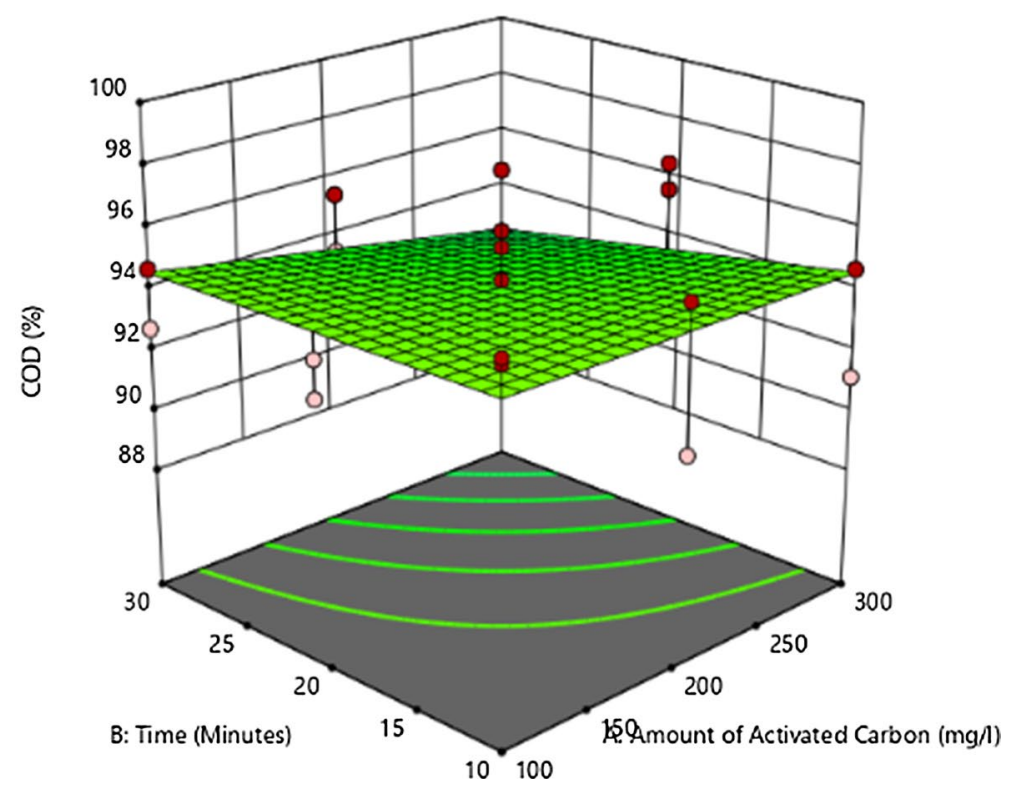

Fig. 4 Composite RSM graph showing the effects of various process parameters on COD removal efficiency of activated carbon prepared using $\mathrm{H}_{3} \mathrm{PO}_{4}$ as an activation agent 


\section{COD removal efficiency of activated carbon prepared using $\mathrm{HNO}_{3}$}

The effects of different amounts of activated carbon and different reaction times on COD removal efficiency for the activated carbon made using $\mathrm{HNO}_{3}$ are presented in Fig. 5 . The removal efficiency was found to be between 96.45 and $88.45 \%$; it was found that the COD removal efficiency increases with an increase in the reaction time and amount of activated carbon. Maximum COD removal was observed at $30 \mathrm{~min}$, and $300 \mathrm{mg} / \mathrm{l}$ activated carbon dose. Minimum COD removal was observed at $10 \mathrm{~min}$ reaction time and $100 \mathrm{mg} / \mathrm{l}$ dose. In a study, Yakubu et al. (2008) reported $91 \%$ removal of COD by the date seed activated carbon prepared using $\mathrm{ZCl}_{2}$ as an activation agent; however, in the present study, $96 \%$ of maximum COD removal was observed. It indicates that $\mathrm{HNO}_{3}$ is the stronger activation agent than $\mathrm{ZCl}_{2}$, which is also reported in the literature (Ademiluyi and David-West 2012).

\section{COD removal efficiency of activated carbon prepared using $\mathrm{H}_{2} \mathrm{SO}_{4}$}

The effects of different amounts of activated carbon and different reaction times on COD removal efficiency for the activated carbon prepared using $\mathrm{H}_{2} \mathrm{SO}_{4}$ are presented in Fig. 6 . As shown in the figure maximum, $98.58 \%$ COD removal was observed at $30 \mathrm{~min}$ reaction time, and $300 \mathrm{mg} / \mathrm{l}$ activated carbon dose. Minimum 91.65\% COD removal was found at $10 \mathrm{~min}$ reaction time, and $100 \mathrm{mg} / \mathrm{l}$ activated carbon dose. The activated carbon prepared using $\mathrm{H}_{2} \mathrm{SO}_{4}$ shows better removal than its counterparts in this study, which might be because $\mathrm{H}_{2} \mathrm{SO}_{4}$ is a strong acid that could have been contributed to more activation, showing more voids (Fig. 3).

\section{Optimization of process parameters}

The set of optimized process parameters for the best result using response surface methodology is shown in Fig. 7. These sets of parameters can be selected to achieve high removal of COD with utilization less time and resources. As shown in Fig. 7, $\mathrm{H}_{2} \mathrm{SO}_{4}$ appeared to be the best activation agents among its counterparts in the study. The optimum dose was found to be $300 \mathrm{mg} / \mathrm{l}$, and the optimum reaction time was $10 \mathrm{~min}$. By this set of conditions, $96.3 \%$ of COD removal could be achieved. The desirability of this set is said to be 0.769 , which is good, and this is one of the 31 combinations given by RSM.

\section{Conclusion}

It can be concluded that the removal of pollutants increases with the increase in the time and concentration of AC. The surface area of activated carbon was found to be large and has lots of pores of different sizes and shapes, and presence

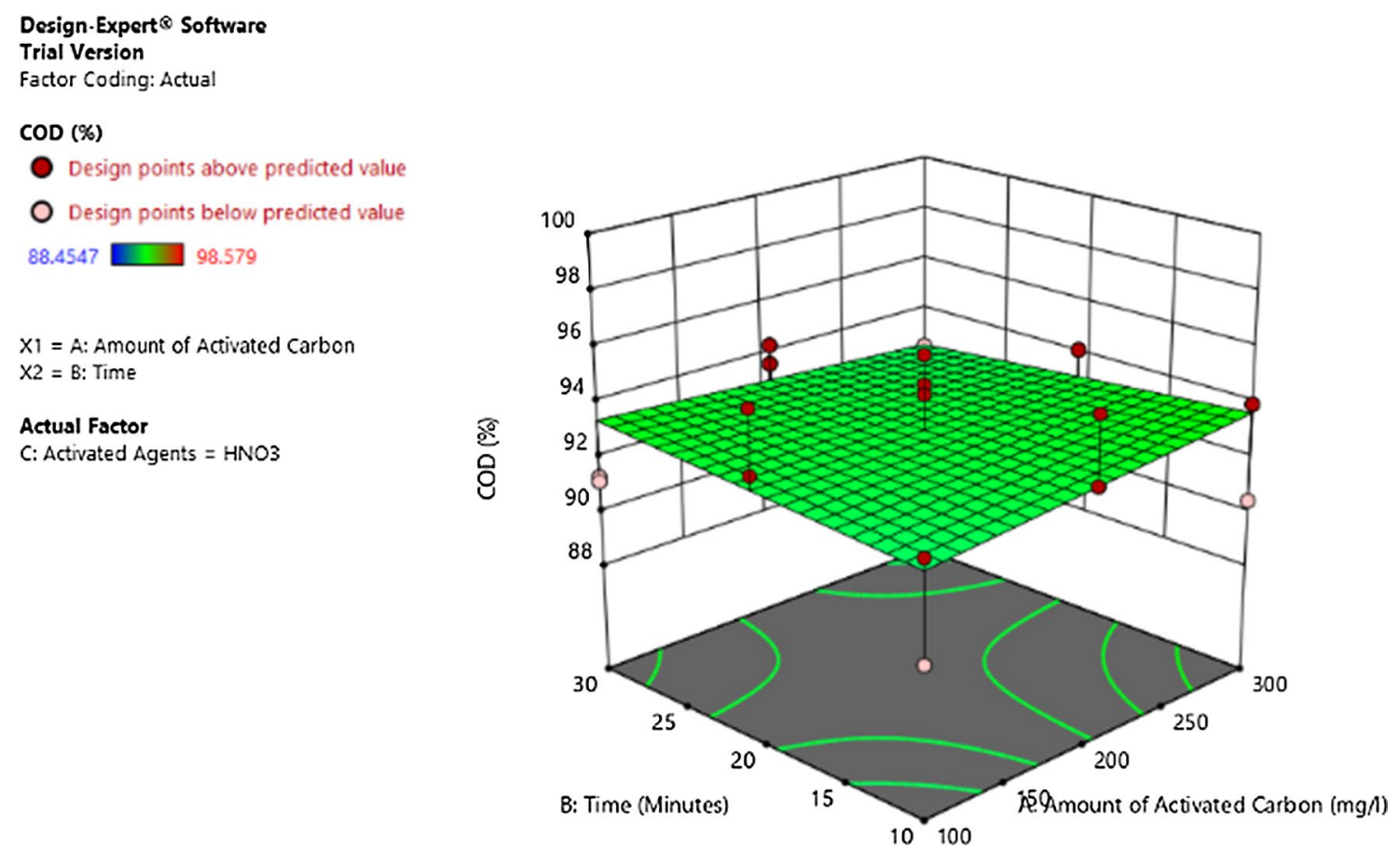

Fig. 5 Composite RSM graph showing the effects of various process parameters on COD removal efficiency of activated carbon prepared using $\mathrm{HNO}_{3}$ as an activation agent 


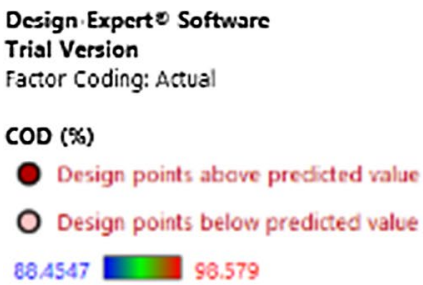

\section{Actual Factor}

C: Activated Agents $=\mathrm{H} 2 \mathrm{SO} 4$

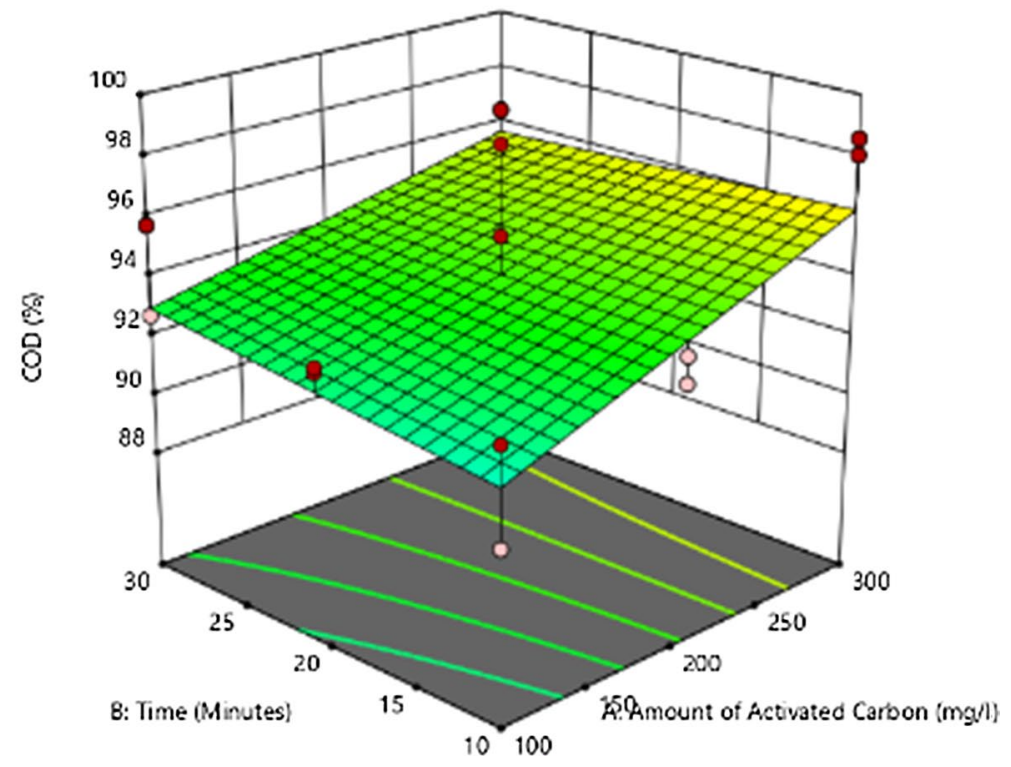

Fig. 6 Composite RSM graph showing the effects of various process parameters on COD removal efficiency of activated carbon prepared using $\mathrm{H}_{2} \mathrm{SO}_{4}$ as an activation agent

Fig. 7 Set of the optimized process parameters for the optimum removal of COD developed using RSM
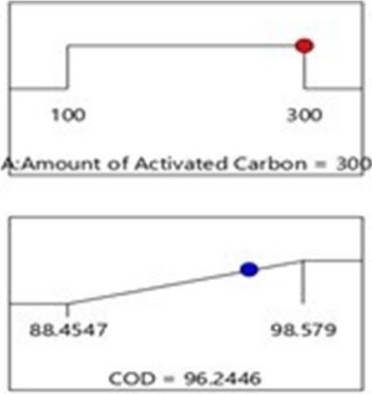

Desirability $=0.769$ Solution 1 out of 31
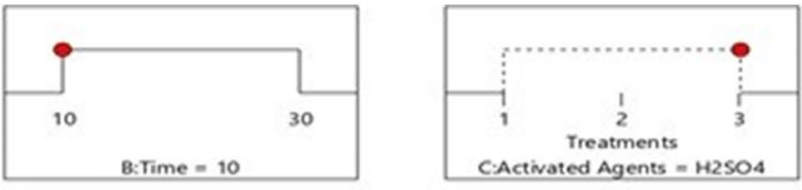

of various elements with a high amount of carbon was also observed in the activated carbon prepared using $\mathrm{H}_{2} \mathrm{SO}_{4}$ activation. Among the three activation agents, $\mathrm{H}_{2} \mathrm{SO} 4$, $\mathrm{HNO}_{3}$, and $\mathrm{H}_{3} \mathrm{PO}_{4}$, the activated carbons prepared using $\mathrm{H}_{2} \mathrm{SO}_{4}$ show better results in terms of pollution removal, which may be due to better activation occurred in case of $\mathrm{H}_{2} \mathrm{SO}_{4}$ acid as it is considered stronger acid than other two. The maximum COD removal of $98.58 \%$ was obtained. Optimization results show that $96.3 \%$ COD removal can be achieved by using $300 \mathrm{mg} / \mathrm{l}$ activated carbon prepared using $\mathrm{H}_{2} \mathrm{SO}_{4}$ acid at $10 \mathrm{~min}$ reaction time. It can also be concluded that eco-friendly, cost-effective activated carbon can produce using date seed. The use of low-cost adsorbents material to produce activated carbon for wastewater treatment will be an alternative to the expensive method (commercial activated carbon like coal and wood). And by using organic waste to make low-cost activated carbon will reduce the load of organic waste in the landfill. By using response surface methodology, process parameters can be optimized to achieve desirable pollution removal at optimum resource and time.

Funding No funding to declare.

\section{Compliance with ethical standards}

Conflict of interest The authors declare that they have no conflict of interest. 
Open Access This article is licensed under a Creative Commons Attribution 4.0 International License, which permits use, sharing, adaptation, distribution and reproduction in any medium or format, as long as you give appropriate credit to the original author(s) and the source, provide a link to the Creative Commons licence, and indicate if changes were made. The images or other third party material in this article are included in the article's Creative Commons licence, unless indicated otherwise in a credit line to the material. If material is not included in the article's Creative Commons licence and your intended use is not permitted by statutory regulation or exceeds the permitted use, you will need to obtain permission directly from the copyright holder. To view a copy of this licence, visit http://creativecommons.org/licenses/by/4.0/.

\section{References}

Ademiluyi FT, David-West EO (2012) Effect of chemical activation on the adsorption of heavy metals using activated carbons from waste materials. ISRN Chem Eng 2012:1-5. https://doi. org/10.5402/2012/674209

APHA/AWWA/WEF (2005) Standard methods for the examination of water and wastewater, 21 st edn. Washington, DC

Azevedo DCS, Araújo JCS, Bastos-Neto M, Torres AEB, Jaguaribe EF, Cavalcante CL (2007) Microporous activated carbon prepared from coconut shells using chemical activation with zinc chloride. Microporous Mesoporous Mater 100(1-3):361-364. https://doi.org/10.1016/J.MICROMESO.2006.11.024

Bansode RR, Losso JN, Marshall WE, Rao RM, Portier RJ (2004) Pecan shell-based granular activated carbon for treatment of chemical oxygen demand (COD) in municipal wastewater. Bioresour Technol 94(2):129-135. https://doi.org/10.1016/J. BIORTECH.2003.12.009

Benadjemia M, Millière L, Reinert L, Benderdouche N, Duclaux L (2011) Preparation, characterization and Methylene Blue adsorption of phosphoric acid activated carbons from globe artichoke leaves. Fuel Process Technol 92(6):1203-1212. https ://doi.org/10.1016/j.fuproc.2011.01.014

Bouchelta C, Medjram MS, Bertrand O, Bellat J-P (2008) Preparation and characterization of activated carbon from date stones by physical activation with steam. J Anal Appl Pyrolysis 82(1):70-77. https://doi.org/10.1016/j.jaap.2007.12.009

Corcho-Corral B, Olivares-Marín M, Fernández-González C, Gómez-Serrano V, Macías-García A (2006) Preparation and textural characterisation of activated carbon from vine shoots (Vitis vinifera) by $\mathrm{H}_{3} \mathrm{PO}_{4}$ - chemical activation. Appl Surf Sci 252(17):5961-5966. https://doi.org/10.1016/j.apsus c. 2005.11 .007

De Gisi S, Lofrano G, Grassi M, Notarnicola M (2016) Characteristics and adsorption capacities of low-cost sorbents for wastewater treatment: a review. Sustain Mater Technol 9:10-40. https:// doi.org/10.1016/J.SUSMAT.2016.06.002

Deng H, Yang L, Tao G, Dai J (2009) Preparation and characterization of activated carbon from cotton stalk by microwave assisted chemical activation-application in methylene blue adsorption from aqueous solution. J Hazard Mater 166(2):1514-1521. https ://doi.org/10.1016/j.jhazmat.2008.12.080

El-Sayed GO, Yehia MM, Asaad AA (2014) Assessment of activated carbon prepared from corncob by chemical activation with phosphoric acid. Water Resour Ind 7-8:66-75. https://doi. org/10.1016/j.wri.2014.10.001

Ghorbani F, Kamari S, Zamani S, Akbari S, Salehi M (2020) Optimization and modeling of aqueous $\mathrm{Cr}(\mathrm{VI})$ adsorption onto activated carbon prepared from sugar beet bagasse agricultural waste by application of response surface methodology. Surf Interfaces 18:100444. https://doi.org/10.1016/J.SURFIN.2020.100444
Hadoun H, Sadaoui Z, Souami N, Sahel D, Toumert I (2013) Characterization of mesoporous carbon prepared from date stems by $\mathrm{H}_{3} \mathrm{PO}_{4}$ chemical activation. Appl Surf Sci 280:1-7. https://doi. org/10.1016/j.apsusc.2013.04.054

Haimour NM, Emeish S (2006) Utilization of date stones for production of activated carbon using phosphoric acid. Waste Manag 26(6):651-660. https://doi.org/10.1016/j.wasman.2005.08.004

Islam MA, Ahmed MJ, Khanday WA, Asif M, Hameed BH (2017) Mesoporous activated coconut shell-derived hydrochar prepared via hydrothermal carbonization- $\mathrm{NaOH}$ activation for methylene blue adsorption. J Environ Manag 203:237-244. https://doi. org/10.1016/J.JENVMAN.2017.07.029

Karimifard S, Alavi Moghaddam MR (2018) Application of response surface methodology in physicochemical removal of dyes from wastewater: a critical review. Sci Total Environ 640-641:772_ 797. https://doi.org/10.1016/J.SCITOTENV.2018.05.355

Li W, Peng J, Zhang L, Xia H, Li N, Yang K, Zhu X (2008) Investigations on carbonization processes of plain tobacco stems and $\mathrm{H}_{3} \mathrm{PO}_{4}$-impregnated tobacco stems used for the preparation of activated carbons with $\mathrm{H}_{3} \mathrm{PO}_{4}$ activation. Ind Crops Prod 28(1):73-80. https://doi.org/10.1016/j.indcrop.2008.01.006

Liew RK, Chai C, Yek PNY, Phang XY, Chong MY, Nam WL, Su MH, Lam WH, Ma NL, Lam SS (2019) Innovative production of highly porous carbon for industrial effluent remediation via microwave vacuum pyrolysis plus sodium-potassium hydroxide mixture activation. J Clean Prod 208:1436-1445. https://doi. org/10.1016/J.JCLEPRO.2018.10.214

Lua AC, Yang T (2005) Characteristics of activated carbon prepared from pistachio-nut shell by zinc chloride activation under nitrogen and vacuum conditions. J Colloid Interface Sci 290(2):505513. https://doi.org/10.1016/j.jcis.2005.04.063

Mohammad Razi MA, Al-Gheethi A, Al-Qaini M, Yousef A (2018) Efficiency of activated carbon from palm kernel shell for treatment of greywater. Arab J Basic Appl Sci 25(3):103-110. https ://doi.org/10.1080/25765299.2018.1514142

Mohan D, Sarswat A, Singh VK, Alexandre-Franco M, Pittman CU (2011) Development of magnetic activated carbon from almond shells for trinitrophenol removal from water. Chem Eng J 172(2):1111-1125. https://doi.org/10.1016/j.cej.2011.06.054

Njoku VO, Hameed BH (2011) Preparation and characterization of activated carbon from corncob by chemical activation with $\mathrm{H}_{3} \mathrm{PO}_{4}$ for 2,4-dichlorophenoxyacetic acid adsorption. Chem Eng J 173(2):391-399. https://doi.org/10.1016/j. cej.2011.07.075

Norouzi S, Heidari M, Alipour V, Rahmanian O, Fazlzadeh M, Mohammadi-moghadam F, Nourmoradi H, Goudarzi B, Dindarloo K (2018) Preparation, characterization and $\mathrm{Cr}(\mathrm{VI})$ adsorption evaluation of $\mathrm{NaOH}$-activated carbon produced from Date Press Cake; an agro-industrial waste. Bioresour Technol 258:48-56. https://doi.org/10.1016/J.BIORTECH.2018.02.106

Olivares-Marín M, Fernández-González C, Macías-García A, GómezSerrano V (2006) Preparation of activated carbons from cherry stones by activation with potassium hydroxide. Appl Surf Sci 252(17):5980-5983. https://doi.org/10.1016/j.apsusc.2005.11.018

Puziy AM, Poddubnaya OI, Martínez-Alonso A, Suárez-Garćía F, Tascón JMD (2002) Characterization of synthetic carbons activated with phosphoric acid. Appl Surf Sci 200(1-4):196-202. https:// doi.org/10.1016/S0169-4332(02)00883-8

Saleem J, Shahid U Bin, Hijab M, Mackey H, McKay G (2019) Production and applications of activated carbons as adsorbents from olive stones. Biomass Convers Biorefin 9(4):775-802. https://doi. org/10.1007/s13399-019-00473-7

Şentorun-Shalaby Ç, Uçak-Astarlıŏ̆lu MG, Artok L, Sarıcı Ç (2006) Preparation and characterization of activated carbons by onestep steam pyrolysis/activation from apricot stones. Microporous 
Mesoporous Mater 88(1):126-134. https://doi.org/10.1016/j.micro meso.2005.09.003

Shukla SK, Al Mushaiqri NRS, Al Subhi HM, Yoo K, Al Sadeq H (2020) Low-cost activated carbon production from organic waste and its utilization for wastewater treatment. Appl Water Sci 10(2):62. https://doi.org/10.1007/s13201-020-1145-z

Soares Maia DA, Sapag K, Toso JP, López RH, Azevedo DCS, Cavalcante CL, Zgrablich G (2010) Characterization of activated carbons from peach stones through the mixed geometry model. Microporous Mesoporous Mater 134(1):181-188. https://doi. org/10.1016/j.micromeso.2010.05.024

Sudaryanto Y, Hartono SB, Irawaty W, Hindarso H, Ismadji S (2006) High surface area activated carbon prepared from cassava peel by chemical activation. Bioresour Technol 97(5):734-739. https ://doi.org/10.1016/j.biortech.2005.04.029

Tancredi N, Medero N, Möller F, Píriz J, Plada C, Cordero T (2004) Phenol adsorption onto powdered and granular activated carbon, prepared from Eucalyptus wood. J Colloid Interface Sci 279(2):357-363. https://doi.org/10.1016/j.jcis.2004.06.067

Thamilselvi V, Radha KV (2017) Silver nanoparticle loaded corncob adsorbent for effluent treatment. J Environ Chem Eng 5(2):18431854. https://doi.org/10.1016/j.jece.2017.03.020

Topal M, Arslan Topal EI (2020) Optimization of tetracycline removal with chitosan obtained from mussel shells using RSM. J Ind Eng Chem. https://doi.org/10.1016/J.JIEC.2020.01.013
Uçar S, Erdem M, Tay T, Karagöz S (2009) Preparation and characterization of activated carbon produced from pomegranate seeds by $\mathrm{ZnCl}_{2}$ activation. Appl Surf Sci 255(21):8890-8896. https:// doi.org/10.1016/j.apsusc.2009.06.080

Valizadeh S, Younesi H, Bahramifar N (2016) Highly mesoporous $\mathrm{K}_{2} \mathrm{CO}_{3}$ and $\mathrm{KOH} /$ activated carbon for SDBS removal from water samples: batch and fixed-bed column adsorption process. Environ Nanotechnol Monit Manag 6:1-13. https://doi.org/10.1016/J. ENMM.2016.06.005

Yakubu M, Gumel M, Abdullahi A (2008) Use of activated carbon from date seeds to treat textile and tannery effluents. Afr J Sci Technol 9(1):39-49

Zięzio M, Charmas B, Jedynak K, Hawryluk M, Kucio K (2020) Preparation and characterization of activated carbons obtained from the waste materials impregnated with phosphoric acid(V). Appl Nanosci. https://doi.org/10.1007/s13204-020-01419-6

Publisher's Note Springer Nature remains neutral with regard to jurisdictional claims in published maps and institutional affiliations. 